\title{
thelomj
}

Letters Homoeopathic product licence

\section{Back to square one}

BMJ 2009; 338 doi: http://dx.doi.org/10.1136/bmj.b2332 (Published 10 June 2009) Cite this as: BMJ 2009;338:b2332

\section{Stephen J Evans, professor of pharmacoepidemiology 1}

${ }^{1}$ London School of Hygiene and Tropical Medicine, London WC1E 7HT

stephen.evans@Ishtm.ac.uk

It is tragic that we now have a respected body, the Medicines and Healthcare products Regulatory Agency (MHRA), granting a licence for a product for which there is not only no evidence of efficacy but good evidence against any efficacy.1 I have some sympathy with the MHRA in the face of a European Directive which has to be obeyed but which is almost totally irrational. However, I think that because "efficacy" appears in the directive and there is evidence against efficacy, it could have resisted granting a licence.

This fiasco takes us back to the days before drug regulation was introduced, partly to prevent the hazards of snake oil-type remedies. While this product may have no benefit, it probably has no direct harm either. But it may have major indirect harms-not only in individual patients who may not benefit from other effective remedies but also in a general sense by undermining the rational basis for medicine.

\section{Notes}

Cite this as: $B M J$ 2009;338:b2332

\section{Footnotes}

- Competing interests: SJE is a former employee of the UK Medicines Control Agency (now MHRA) and a member of the Pharmacovigilance Working Party of the CHMP at the European Medicines Agency.

\section{References}

1. Cohen D. Drugs agency grants its first licence to homoeopathic product. BMJ 2009;338:b2055. (20 May.) 